\title{
5 \\ Global Health, Tuberculosis and Local Health Campaigns: Reinforcing and Reshaping Health and Gender Inequalities in Lihir, Papua New Guinea
}

\author{
Susan R. Hemer
}

\section{Introduction}

The social inequalities that drive tuberculosis (TB) have long been known to and discussed by health professionals and researchers. Medical anthropologists such as Paul Farmer have commented that physicians and public health workers are well aware of the social forces that structure who becomes ill and who has access to care (2000). TB 'is quintessentially a social disease ... a marker of the contextual impacts of disadvantage and social disruption' (Mason \& Degeling, 2016, p. 32). Rates of TB incidence are 'closely correlated with social and economic determinants such as the human development index, access to water sanitation and child mortality' and cluster among the poor, hungry and ethnic minorities (Hargreaves et al., 2011, p. 654). Structural determinants such as global socioeconomic inequalities, population growth, population mobility and rapid urbanisation give rise to social determinants such as malnutrition, poor and overcrowded housing and a range of barriers to access to care 
(Hargreaves et al., 2011, 655). Therefore, TB is a disease of povertythose people most likely to be exposed to infection are precisely those least able to seek diagnosis and continue the lengthy treatment required for cure.

These insights have been difficult to translate into policies that shape clinical practice and knowledge of these broader structures and determinants is often suppressed (Farmer et al., 2006). In the translation to policy, targets and practice, the focus is generally narrowed to the clinical aspects of this disease. The social inequalities that drive TB become submerged, while individual cases and hosts become the centre of biomedical attention and blame. As Farmer and his colleagues have stated, 'structural violence is often embedded in longstanding ... social structures ... Because they seem so ordinary in our ways of understanding the world, they appear almost invisible' (Farmer et al., 2006, p. 1686). These elisions in the ways that TB is understood, spoken about and treated perpetuate structural violence against people with the disease, which reinforces or compounds existing inequalities.

Globally, TB is the leading cause of death from a single infectious agent. In 2017, approximately 10 million people developed it (World Health Organization [WHO], 2018). At the turn of the century, it was estimated that approximately 2 billion people, or one-third of the world's population, were infected with latent TB (Farmer, 2000, p. 184). The World Health Organization (WHO) classifies 30 countries as being 'High TB Burden' countries, and these account for 87 per cent of cases. Most high-income countries have low incidence rates-this is a clear indicator of the relationship between TB and poverty (WHO, 2018). Globally, it has been stated that three basic factors drive TB: malnutrition, indoor air pollution (e.g. that caused by the use of solid fuels for cooking) and smoking (Elbeck, 2015). Within countries, people of lower socioeconomic status are more at risk: TB's 'mode of transmission and disease aetiology (whereby transmission is exacerbated by extended and close contact with persons in settings with little sunlight and air circulation and by comorbidities that reduce immunity) ensures that deaths caused by $\mathrm{TB}$ are disproportionately found in persons of lower SES [socioeconomic status]' (Silva, Dawson \& Upshur, 2016, p. 76). Farmer has commented that the presence of the disease is the 'biological expression of social inequalities' (2001, p. 262). Further evidence of inequality driving TB is observed in patterns of infection-there exist clear gender and age disparities in rates of TB. Rates of male to female infection range from 1:1 to 3:1, with an average 
of 1.7:1 (Mason et al., 2016), and those above the age of 50 shoulder the highest burden of TB. Researchers have debated whether these gender disparities are 'real' or an artefact of access to health care and diagnosis, or whether they perhaps reflect smoking and other comorbidities rather than a greater susceptibility of men to the disease (see e.g. Feng et al., 2012; Ting et al., 2014; Wingfield et al., 2016).

The first-ever United Nations (UN) General Assembly high-level meeting about TB was held in September 2018. A declaration followed to accelerate progress towards the 'End TB' target of disease eradication by 2030. The UN Deputy Secretary-General Amina Mohammed explicitly noted the social basis of $\mathrm{TB}$, including 'poverty, inequality, urbanisation, migration and conflict', and the need for an 'all-systems approach that accounts for the social drivers that perpetuate its spread' (United Nations, 2018). However, Dixon and Macdonald have argued that 'for all the talk about systemic drivers and inhibitors at the meeting, the five "key asks" in the declaration remained highly biomedical in approach, focused on "reaching" "vulnerable" people with drugs, diagnostics and vaccines' (2018, p. 248). Such an approach, with a focus on biomedicine and targets for control, reinforces existing efforts in global health. There exists a distinct preference for work on health conditions where measurable targets can be set and progress then monitored, which helps to reassure donor bodies that funds are being spent appropriately. This emphasis on 'narrow, vertical, technologically driven disease programmes' (Dixon \& Macdonald, 2018, p. 250) deflects efforts and funding away from comprehensive primary health care and from conditions that are not so easily measured.

In Papua New Guinea (PNG), high levels of TB infection have gained international focus, large aid donations, the attention of non-governmental organisations and the press, in addition to the label of 'emergency'particularly in the case of the emergence of high levels of drug-resistant TB in Daru, Western Province, on the southern coast of PNG. Programs seek to identify 'hot spots' (areas of high infection) and people with active infections; they then work to control people's movement until they are non-infectious and survey medication compliance through the Directly Observed Treatment, Short Course (DOTS) program. Issues of treatment failure are generally explained in terms of individuals' noncompliance; the socioeconomic and gendered contexts of such 'failures' are rendered largely invisible and, therefore, irresolvable. 
In this chapter, I focus on the TB situation in the Lihir Islands in New Ireland Province, to provide a case study of structural inequalities that shape TB and those ways in which TB compounds various inequalities facing Papua New Guineans. Due to the presence of a large-scale gold mine, and all the 'development' that extraction brings to an area, Lihir possesses some of the best health care available in the country. However, within the island group, there exist disparities in access to health care that shape people's access to TB diagnosis and treatment. Through an ethnographic analysis of specific cases of TB, in the context of the Lihir Islands, this chapter investigates how relations of inequality shape people's access to and experiences of diagnosis and treatment. In a country in which healthcare provision is often compromised or entirely lacking, there exist challenges of physical access to health services and healthcare information and education is not evenly distributed, how might TB be shaped by these inequities and, in turn, compound them? Finally, this chapter reflects on how inequalities are perpetuated and influence people's chances of life and death and, further, how large-scale mining exacerbates these issues.

\section{Global Health and Tuberculosis}

In recent years, anthropologists have analysed how global health policies and priorities are understood and applied locally (e.g. Janes \& Corbett, 2009; Harper \& Parker, 2014; Parker \& Allen, 2014). Many of these contributions have critiqued the vertical nature of interventions that have a single-disease focus, rather than a comprehensive approach to health and healthcare systems, and that are driven top-down by the priorities of the Global North (Magnussen, Ehiri \& Jolly, 2004). Until the 1980s, the WHO took a holistic view of health, following the agreements for broad primary healthcare initiatives at Alma Ata in the 1970s. The WHO has sought to develop broader programs for health and to create approaches that rely on more than a singular focus to manage diseases. Approaches such as preventive chemotherapy are often combined with disease management, broader research programs, a focus on health systems, health education and the provision of safe water, sanitation and hygiene (WHO, 2012 , p. 5). This broader focus can also be observed in UN comments about the latest efforts in fighting TB. 
However, these broader components of health programs set at international levels are frequently jettisoned when disease management targets are set at the local level because of contextual factors or insufficient funding. In the late 1980s and early 1990s, there occurred a shift to vertical or disease point programs rather than improving health services and comprehensive national health policies (Elbeck, 2015): a 'resurgence of selective forms of primary care and vertical public health programs' (Janes \& Corbett, 2009 , p. 174). This has been the case for diseases that were named in the Millennium Development Goals, such as TB (Harper, 2010) and the 'Neglected Tropical Diseases', which gained importance in the early 2000s. Since this time, the WHO has consistently developed policies that target specific diseases with specific interventions; funding models support this approach.

In 1993, the WHO declared a 'global health emergency' in relation to TB and developed DOTS as the key strategy for global control of the disease. DOTS includes diagnosis by sputum smear microscopy, a standardised supervised treatment regime, an uninterrupted drug supply and a recording and reporting system. The WHO 'began to claim that TB problem [sic] could be solved by new and expensive drugs, vaccines, and new technological developments that would enable the rapid diagnosis of resistant cases' (Elbeck, 2015, p. 75). DOTS remained central in the 2006 STOP TB strategy, which aimed to manage more complex forms of TB, including multidrug-resistant TB (MDR-TB) and HIV-TB coinfection (WHO, 2006).

\section{Tuberculosis in Papua New Guinea}

The most recent available statistics for TB in PNG indicate that there were over 28,000 case notifications to the WHO in 2018. This is an incidence of 432 in 100,000, which equates to the second-worst incidence in the Western Pacific (behind the Philippines) and the sixthworst in the world. Mortality from TB alone (e.g. excluding HIV-TB) is 52 in 100,000 (WHO, 2019); this statistic has worsened in recent years from 40 in 100,000 in 2014 (WHO, 2015). Statistics for the number of case notifications have worsened in the last 10 years; however, it is unclear whether this is due to increased detection of cases or a worsening situation. The WHO estimated a total of 17,000 cases in the country in 2009nearly double this number of cases were found in 2017 (Department of 
Health, Government of Papua New Guinea, 2011). Despite considerable attention and funding in recent years, including the aim for an 85 per cent cure rate (for detected cases), only 68 per cent of treatment is successful in notified cases. However, this rate is slightly more successful ( 75 per cent) in cases of MDR-TB.

PNG's TB program attracts high levels of funding from external donors, such as the Global Fund and bilateral aid programs, resulting in pressure to comply with international standards and procedures. In recent years, Australia has also expressed significant concern about TB, due to the proximity of Daru to the Torres Strait and the tendency for people with TB to cross the border for treatment (Horner, Wood \& Kelly, 2013; Thomas et al., 2010). With this in mind, donors have focused on identifying 'hot spots' of TB infection and increasing efforts in those areas-in particular, Western Province, Gulf Province, the National Capital and, more recently, West New Britain (Aia et al., 2018; Cross et al., 2014). Outside these areas, the TB program has generally garnered less attention and lower priority, although some epidemiological research has aimed to understand rates of infection in other places in the country, such as the recent overview of surveillance data (Aia et al., 2018) and work in the Eastern Highlands, Madang and Milne Bay (Ley, 2014; Ley, Riley \& Beck, 2014; Ley et al., 2014).

PNG has adopted the WHO-recommended DOTS program to address TB. Ideally, pulmonary TB should be diagnosed through a sputum smear that is microscopically identified as positive for TB bacteria. The disease remains contagious for some weeks after treatment begins; often, if facilities are available, people are hospitalised and isolated during this time. Next, patients go home to continue daily treatment with a mixture of medications; their compliance should be monitored by a nominated person (often a health worker) who watches them swallow their medication. These medications are provided in standardised combinations and quantities through the global STOP TB campaign. PNG aims for 100 per cent DOTS compliance in all health facilities; yet, it seems that many facilities do not practice DOTS as fully recommended, sending patients home with months of drug supplies but little to no further monitoring (Aia et al., 2018).

Diagnosis, as recommended by $\mathrm{WHO}$, depends on the availability of microscopy. As recently as 2016, there were only 114 laboratories in PNG with TB testing capabilities (for a population of approximately 
8 million people). PNG delivers TB services to the population through its decentralised health service, comprising provincial and district hospitals, health centres, health sub-centres and aid posts. In 2012, there were 306 hospitals and health centres, 428 health sub-centres and nearly 3,500 aid posts (Department of Health, Government of Papua New Guinea, 2012). TB diagnosis and treatment is managed through 275 health facilities that are accredited as 'basic management units' (BMU): the initial point for collecting TB data (Aia et al., 2018). These numbers indicate that most health facilities do not have laboratory facilities, nor are they considered to be BMUs; further, many BMUs do not have laboratory capabilities. Chest $\mathrm{x}$-rays are still used as a form of alternative diagnosis in many larger health facilities; however, in many parts of PNG, there are either no x-ray machines, no power or the chemicals required to perform an $\mathrm{x}$-ray are out of stock. Therefore, this form of diagnosis is often unavailable (see e.g. Street, 2014). These variations in health service provision often depend on the remoteness of the area-many areas have no healthcare services at all, or services that are rarely staffed or are staffed but lacking in facilities or medications (Howes et al., 2014; Wiltshire \& Mako, 2014). Further, almost half of TB cases that are diagnosed in PNG are extra-pulmonary, which is more challenging to diagnose (Norbis et al., 2014); therefore, considerable misdiagnosis and delayed diagnosis are likely.

Worldwide, MDR-TB is becoming an increasing problem; an average of 3.5 per cent of new cases are multidrug-resistant. In PNG, data is by no means comprehensive. Estimates range from 3.4 per cent of new cases (the official rate listed by the WHO [2018]) to as low as 2.8 per cent of cultured samples in a survey in three major towns across three provincesMadang, Goroka and Alotau (Ley et al., 2014). At the upper end of the estimates, there was 9 per cent MDR-TB in samples from Gulf Province (Cross et al., 2014) to as high as 25 per cent in samples taken in the Western Province during 2000 to 2006 (Gilpin et al., 2008). Extensively drug-resistant TB (XDR-TB) has also been reported in PNG since 2012, suggesting that drug-resistant $\mathrm{TB}$ is becoming a very significant problem in PNG.

For the country as a whole, TB presents a major issue in terms of the rates of infection and mortality, management of drug-resistant $\mathrm{TB}$ and the provision of successful treatment. Within the country, variable rates of TB infection and treatment highlight socioeconomic inequalities in addition to the unequal provision of (and access to) health care. 


\section{Tuberculosis and Health Care Provision in Lihir}

Lihir is a group of five islands located to the north-east of mainland New Ireland, comprising a large southern island, Niolam, which is approximately $14 \mathrm{~km}$ wide and $21 \mathrm{~km}$ long, and four smaller 'outer' islands to the north, the conjoined Malie and Sinambiet, Masahet and Mahur. I have worked in Lihir since the late 1990s, including doctoral fieldwork on the northernmost island, Mahur (1997-98), a research position located mostly on Niolam focusing on community health and gender with a mining company (2000-02) and independent return visits in 2003, 2004, 2011,2012, 2014, 2016 and 2018, which primarily focused on health and gender.

Niolam has hosted a large-scale gold mining operation since 1997; mining is now predicted to continue until approximately 2050. Mining has brought 'development' to this formerly remote, subsistence-based island population in forms including a ring road and vehicles on the main island, wage employment and businesses, increased alcohol consumption, improved health and education services and migration from elsewhere in PNG. The population has swelled from about 7,000, in the late 1990s, to approximately 16,000 Lihirians and 9,000 migrants (some of whom are employed with local companies): a combined population of about 25,000. Early in the development of the mine, certain areas within Lihir were designated as 'affected areas'-those villages closer to mine lease areas that include the mine pit and plant site, township, accommodation areas and airport. These communities were given access to comparatively greater benefits in recognition of greater impacts in these areas (see Bainton, this volume). Benefits include electrification, road sealing, regular rubbish removal services, the provision of community infrastructure and specifically negotiated packages to compensate for village relocation or loss of land. Villages outside these areas were effectively designated as 'non-affected' and have comparatively less access to the benefits of mining; this has created an antagonistic situation (Bainton, 2010). There is a 'noticeable decline in the material standards of living with increasing distance from the SML [Special Mining Lease]' (Bainton, 2010, p. 118). In 2000, Malie and Sinambiet islands were recognised as 'affected' following community protests about impacts to the ocean (Bainton, this volume). Overall, these mining and 'development' changes have shaped life on the islands in the last 20 years, including patterns of ill health and the population's access to health care. 
Initially, TB was not highlighted as an issue of concern in Lihir-the baseline health report for the mining project did not mention it once (Taufa et al., 1992). Prior to the commencement of mining, the death register at the Catholic Palie health centre-located on the south end of Niolam - recorded two deaths from TB, in 1991 and 1992, of a total of 18 and 23 deaths in those years, respectively. Records from the time suggest that most people sought care at the centre for births and acute conditions and there were relatively few deaths in the centre. However, data from medical workers of the late 1990s indicated that TB was a focus of medical efforts, with 30 and 39 inpatients treated for TB in 1999 and 2000, respectively. This was recorded at the Lihir Medical Centre (LMC) - the new centre established by the mining company in the northeast corner of Niolam. There were two TB deaths in Lihir in both 1999 and 2000, but five deaths in 2001. TB was noted as a concern in reviews of health in the early 2000s; since this time, the number of TB cases and concern about the disease only seem to have increased (Hemer, 2001). In the early 2000s, there existed sufficient concern such that the mining company commissioned a report on TB in the islands, which noted an increasing number of diagnosed cases from 1997 to 2003 (Johnson, 2004). More recently, there were 74 cases diagnosed in 2013, 88 in 2014 and 96 in 2015. By the end of June 2016, 51 cases had been diagnosed, indicating that another increase was likely. These numbers provide a rate of 384 in 100,000 notified cases in 2015-higher than the national rate of notified cases of 351 in 2014 (WHO, 2015). It was unclear whether this higher rate was due to higher infection rates or was an artefact of better detectionhealth workers with whom I spoke did not have a clear opinion on the issue. This relatively high rate has not been recognised on the national level as a 'hotspot' such as those in Western or Gulf Provinces, which may partly be due to the general lack of government attention to mining enclaves - in practice, these are often regarded as the responsibility of the resource companies operating there.

Prior to mining, from the 1930s onwards, the largest healthcare institution in Lihir was the Catholic-run health centre at the Palie mission station in the south of Niolam. This provided outpatient and inpatient services, with a very basic laboratory and some outreach services for maternal child health, often undertaken by boat. There were also several aid posts dotted around the islands that were staffed by aid post orderlies or, more recently, by community health workers and nurses - these provided basic first aid and medication and referral services. Healthcare services were relatively 
dispersed, and access to them often required lengthy travel by foot or boat. Prior to the construction of the mine and associated infrastructure, the Lihir islands were one of the more neglected areas in New Ireland Province. In her early visits to Lihir, as part of conducting social impact monitoring studies for the mining company, Martha Macintyre recalls that she was 'struck by the relative poverty of people there' (2010, p. x). However, it was hoped that the incoming mine would provide a range of benefits and improve lifestyles, including health.

In terms of current health services, the population of Lihir is served by the Palie Catholic health centre in the south of Niolam, the Masahet health sub-centre located on Masahet island, the LMC near the mining town in the north of Niolam and eight aid posts (six on Niolam, one on Sinambiet and one on Mahur). The LMC was built in 1997 by the mining company to provide services to employees in addition to having a public outpatient and inpatient department, $\mathrm{x}$-ray and laboratory services and various public health outreach services. The LMC is staffed by PNG and expatriate doctors, with at least one doctor always on call, and is run by an international health service provider contracted to the mining company. The LMC provides some of the best health care available in PNG. However, one major issue for health service provision to the islands has been the coordination between different service providersthe government, the Catholic health service and the mining company. For a number of years, the landowners' association also attempted to establish a fourth provider. With a relatively small population, a contained geographical space and a range of providers, positive health outcomes should have resulted. However, in practice, there are many points of disconnection, overlap or confusion about service provision. This is a key contradiction of mining, in which an increase in resources has not necessarily led to improvements in health.

The LMC has been accredited as a BMU for TB; it is a key point of data collection and reporting. Interviewed staff were keen to emphasise that, since 2011, the LMC has been following national TB guidelines for diagnosis and treatment. In 2013, the LMC obtained one of the first GeneXpert machines in PNG for testing TB-in 2016, there were still only a dozen machines in the country. This acquisition improved diagnostic capabilities and permitted testing for some drug sensitivity. The GeneXpert machine has led to the early detection of more pulmonary cases. Concurrently, the LMC built a specialist ward to house TB patients, outside the air-conditioning system used for the rest of the hospital. 
The procedure in Lihir is this: most patients, particularly pulmonary cases (due to higher infectivity), are to be admitted as inpatients for the first two to four weeks of treatment. During this time, the focus is on infection control, health care for serious complications of TB (e.g. collapsed lungs) and medication provided in fixed-dose combination. Drug supply in Lihir is excellent in comparison with many other places in the country-the presence of a major mining company means that transport and logistics are functional.

It was quite clear to me in my recent visits to the islands (2016 and 2018) that clinical management of TB follows global best practice health guidelines and is some of the best in the country. Moreover, Lihir has healthcare resources, such as staffing, facilities and medication supply that are difficult to procure elsewhere. Despite this, in the discussion that follows, I trace a number of cases of TB in Lihir that demonstrate the ways in which structural inequalities shape the diagnosis and treatment of this illness and its impact on people's lives.

\section{Challenges in Accessing Health Care}

Palie health centre is located almost at the end of a sealed road in the south of Lihir. The centre was due to be rebuilt in 2008; however, its current, somewhat dilapidated appearance and occasional holes in the walls signal a lack of updated facilities within. Debates over authority, responsibility and funding have meant that the planned rebuild has not yet occurred; maintenance needs have also largely been ignored. There is one nurse trained in TB management; however, there is no $\mathrm{x}$-ray machine or laboratory facilities to enable diagnosis. Suspected cases of TB (based on clinical signs) are referred for diagnosis to the far superior facilities at the LMC. Treatment of post-diagnosis patients from the south of the island is mostly managed through Palie.

In the early 2000s, the sharp discord between the facilities and expertise available at the LMC and Palie health centre was mitigated by policies in place at the local level that allowed all patients access to the LMC, regardless of their village of origin. Further, LMC doctors provided regular physical visits, radio contact and support for staff at Palie. There was an agreement in place that gave the LMC responsibility for outreach and maternal child health clinics for the northern three islands and the north of Niolam, whereas Palie was responsible for the south of Niolam. 
In more recent years, a growing population and decreasing per capita funding has resulted in the LMC now being responsible for outreach in the north of Niolam, but not on the outer islands - these are now overseen by the government-run Masahet health sub-centre. Although doctors are permitted to provide support to Palie, in practice, this is no longer routinised. Further, there is no longer a Health Extension Officer based at Palie; instead, the highest qualified staff member is a nurse. In terms of TB diagnosis and treatment, it is now considerably more difficult to access health care if a person comes from villages near Palie, because the facilities and expertise available at this health centre are minimal in comparison with those at LMC. Moreover, the ring road past Palie in south-western Niolam is unsealed and has deteriorated to the point that it is sometimes barely passable, creating a barrier to accessible health care for all villagers in that area. It is the responsibility of the local government to maintain (and ultimately seal) this part of the road, as one component of the agreed benefits package for the mining project. In the past, the mining company often took responsibility for maintaining the ring road around the entirety of Niolam; however, it no longer does so. The failure of the government to provide this agreed-upon service or to upgrade the road means that villagers in this area struggle to gain physical access to health care. It also exacerbates the divide between those in the south-west with those in the north and east of the island, who have relatively easy access to the LMC and its superior facilities. For people with TB located in villages on the south-western or western coasts of Niolam, access may sometimes require a boat trip to LMC or Palie. This is also the case for people located on the northern islands. This lack of physical accessibility was raised by one health worker, who stated that the LMC only undertook contact tracing on Niolam rather than the outer islands. Consequently, more cases might be missed or be detected later in the course of the disease. Further, according to this health worker, villages such as Samo and Mazuz (on the south-western coast of Niolam) are located the furthest from the LMC, on the section of unsealed road; therefore, issues of distance and transport cost make defaulting on medications much more likely.

Even when health care is apparently physically accessible, the design or policies of healthcare provision can create challenges for access. Guided by global and national health policies, at both the LMC and Palie, some workers specialise in TB; for example, at the LMC, two health workers under the auspices of the public health team work back-to-back shifts that focus on TB and HIV. This is an unremarkable arrangement; further, the 
link with HIV makes good clinical sense, due to the syndemic relationship between the two. However, for people seeking diagnosis or advice, a visit to the medical centre to see one of these workers may signal (incorrectly or otherwise) to others that the person has HIV. Stigma was raised as an issue for at least one patient who was defaulting on medication; he asked the health worker not to visit him in his place of employment due to fear of repercussions. However, it was unclear to me whether the stigma related to the perception of having TB or the potential link with HIV.

A newly diagnosed TB patient in Lihir, particularly a pulmonary case, will be expected to stay for two to four weeks in the TB ward at the LMC. Those who default on treatment are expected to return and stay for four to six weeks in the ward. To prevent the spread of infection, this ward is located outside the centre's main air-conditioning system, to prevent contagion. The ward is not segregated by gender. Neither is the small TB ward at Palie, which is simply part of the general male ward. A situation in which unrelated males and females sleep within the same room is beyond comprehension in Lihir and probably also other places in PNG. During her study of TB in Lihir in 2004, Penny Johnson recalled at least one female patient who raised this as a concern, because she had had to share space with two male TB patients at LMC, before the dedicated TB ward was built (Johnson, 2004). However, issues of gender collocation were not considered during the planning and building process. Further, in my research, no health worker ever raised this as a concern or even a possible deterrent to diagnosis and treatment.

Only two of the most highly qualified health workers offered information on patterns of infection in TB. One, a doctor, noted that there were three peaks of infection in Lihir: infants who are infected via close contact with their mothers, teenagers who are infected for the first time and older people whose latent TB infection is activated. Another health worker suggested that, some years earlier, it had appeared that migrants were diagnosed more often than locals; however, in recent years, Lihirians were being diagnosed more often. He thought that overcrowding in areas near the mine was an issue for TB infection; based on published accounts of factors contributing to TB infection, this is likely to have been true. ${ }^{1}$

1 At the time of writing, statistics on the distribution of diagnosed cases, defaulting cases or deaths by age, gender or village were unavailable for Lihir or New Ireland Province. Even the PNG data is relatively limited on this issue-the latest WHO report on TB is limited to gendered population distribution graphs (WHO, 2019). Therefore, it is impossible to test assertions about the spread of cases. This lack of data suggests the need for more research across the country. 
These comments are suggestive of structural inequalities driving TB infection, diagnosis and treatment; however, these sorts of reflections were rare. During my fieldwork in Lihir, I was surprised that most health workers had not considered whether rates of TB differed in accordance with sex or age. Nor did they question whether diagnosis and treatment were evenly accessible to all within Lihir (both Lihirians and non-Lihirian migrants) or whether a TB diagnosis had different implications for different members of the population. The majority of health workers were firmly focused on the clinical aspects of work and the attempt to manage the burden of ill health. Even at the national level, structural determinants and inequalities are not prioritised. In searching the most recent statistics, it also became apparent that TB data that is segregated by gender only became available for the whole of PNG in 2019-such information had already been available for all other countries classified as having a high TB burden (WHO, 2019).

Despite mineral wealth and a relatively small land area and population, shifts in policy and accepted practice have exacerbated inequalities in access to health care, rather than fulfilling earlier hopes of improved living conditions. There exist clear disparities and barriers in access to TB-related health care, shaped by physical location, gender and the experience of stigma - challenges that have not been alleviated by the influx of large flows of capital. This is unsurprising because the literature on extractive industries in the PNG context has drawn connections between the income from such projects, social conflict and growing inequalities (Banks, 2008). There is little to no evidence that resource development reduces poverty; in fact, it may perform the opposite or, at minimum, increase disparities (Banks, 2005). Laura Zimmer-Tamakoshi has noted the ways in which both gender and generational inequalities have been exacerbated by mining activity (Zimmer-Tamakoshi, 2016, this volume). Betina Beer has argued that large-scale capitalist projects in the country 'create continuities as well as conflicts with earlier forms of inequality' (2018, p. 348). In the following section, I chart the ways in which social inequalities not only influence TB infection, diagnosis and treatment but also deepen inequalities and poverty. 


\section{Compounding Inequalities}

In June 2016, when I returned to the northernmost island of the Lihir group, Mahur, I found that two girls in their upper teens within the same lineage had recently been diagnosed with TB. I sat with a woman I have known for over 20 years, who told me that her high school-aged daughter had lost a lot of weight and had been coughing. She had been suspected of having TB, and the nurse at the aid post had sent her to the LMC for diagnosis. The daughter was diagnosed with pulmonary TB and hospitalised for some weeks, as is usual practice in Lihir. Following discharge, her family had arranged for her to stay with her mother's sister in a village closer to the LMC (on Niolam) to facilitate easier access to treatment for the required six months. Despite this, when I briefly discussed her case with the LMC, it became apparent that she was behind in her medications and, therefore, considered to be in default on treatment.

Within days, I heard about the second girl in the same kin group, who had been diagnosed with TB of the spine and was being treated on Mahur at the time of my visit. Again, the nurse at the Mahur aid post had suspected TB and referred her to the LMC for diagnosis. Following diagnosis, the girl was sent home to Mahur with a recommendation for nine months of treatment, due to the involvement of the spine and the difficulties associated with using medication to kill bacteria in the bone. I asked the nurse on Mahur about her treatment and prognosis. The nurse was uncertain-about the diagnosis, about her prognosis and whether there would be permanent bone damage. The nurse had no involvement in the ongoing treatment process, which was entirely managed by the LMC on Niolam. Medications were to be picked up once a month by the girl's mother, involving a lengthy and costly round trip by boat to the largest island of Lihir, and given to her daily by her mother. This represents a case of family administration of medication, rather than DOTS by health workers, despite the family living near the Mahur aid post, which provides evidence of a disconnection between health facilities in Lihir and the practical implementation of DOTS.

Both of these girls had been in school prior to illness, but were now unable to attend due to treatment. The first was absent from school due to initial hospitalisation and her subsequent move to a different village to better access treatment. The second was absent from school because the TB in her spine caused difficulties with walking. Health workers confirmed 
that it is common to lose up to a year of schooling when a young person is diagnosed in Lihir. Further, it is likely that some people who develop TB never return to school, given the lengthy treatment process. Such disruption to education is likely to compound any pre-existing socioeconomic inequalities.

In reflecting on these two cases, I realised that both girls were the daughters of unmarried women. It is only via deep familiarity with the Mahur social context that I am able to know that these families were likely to have been less financially secure, with less access to disposable income and, therefore, were less likely to be able to purchase protein to add to meals, and perhaps had smaller houses and gardens than others. As the most distantly located island in the group, Mahur has also benefited the least from the mining project. These girls are likely to have been less well-nourished than some other young people in Lihir-there exist known relationships between poverty, malnutrition and TB (Elbeck, 2015; Ortblad et al., 2015). These families are also more likely to struggle to afford transport to collect medications. A lengthy illness such as TB is likely to compound the precarious position of such families, pushing them deeper into povertyreflecting the global understanding that TB is a driver of poverty (Ortblad et al., 2015).

\section{Individual and Collective Responsibility: Losing Sight of Structural Inequality}

Most health workers with whom I spoke kept attention firmly on clinical aspects of cases and considered individual characteristics of those infected and cultural beliefs about TB as critical for understanding the spread of $\mathrm{TB}$ cases in the islands, rather than considering the relationship between $\mathrm{TB}$ and structural inequalities such as poverty and uneven development. The way in which patients who defaulted on treatment were discussed provides a salient example. An adult Lihirian man had been diagnosed by LMC staff with MDR-TB, following repeated defaulting on TB medications over a number of years. He lived in an 'affected-area' village near the mine on Niolam and LMC staff had been visiting him daily to ensure his compliance with medication and his continued presence at home, because it was likely that he was contagious. They had conducted contact tracing to ensure his family remained free of TB. Staff were concerned that he was developing $\mathrm{XDR}-\mathrm{TB}$, which has a high fatality 
rate. Despite their efforts and ongoing medication, the man's condition worsened, and he eventually died (after I left Lihir). During my time there, what most mattered to health workers was that he defaulted numerous times on ordinary TB treatment, which led to his TB becoming resistant to frontline medications. To them, the most relevant point was the man's noncompliance-he had, in their eyes, created his own difficulties.

It might have been predicted that, because the man lived in a relatively affluent 'affected-area' village, he would be less vulnerable to the influence of structural inequalities. However, such a prediction preferences the immediate relative wealth of these villages over other, more long-term inequalities. Prior to the commencement of mining, some of the villages close to the mine were some of the poorest in the islands. As a childassuming that he had not moved there from elsewhere-this man would probably have been subject to the poverty faced by all Lihirian children. His family most likely cooked over solid fuels (as most families did and many still do), which is a practice clearly linked to susceptibility to TB infection that may stay latent in the body for decades. As an adult, it is also very likely that he smoked and may have been at risk for diabetesthis is becoming increasingly common in affected-area villages, as living standards and consumption patterns suddenly shift, causing significant impact to bodies that were never prepared for high amounts of fat and sugar. ${ }^{2}$ Smoking is one of the key risk factors for TB, as is diabetes. None of the health workers with whom I spoke raised questions regarding where he had contracted TB, whether he had concomitant diabetes or if there was an immune-related reason that the latent TB, which affects the majority of the population, became active in his case. Nor were serious questions raised regarding why he had defaulted numerous times on his medication-he was simply perceived as a 'poor' or 'noncompliant' patient.

Discussions about adherence to TB treatment and noncompliant patients are common both in the literature and on the ground in PNG. As noted by Simpson from Cairns Base hospital, 'the main factors in the survival of tuberculosis [are] related to human nature-people stop taking medicine once they feel better' (2011, p. 759). Ungugo, Hall and Attia (2011, p. 427) have suggested that legislation may be required in PNG to

2 A 2010 demographic health study on the Lihir islands indicated a high prevalence of smoking, at over 55 per cent for all adults (Bentley, 2010, p. 44). The report also identified changing diets and increasing incidence of being overweight or obese as factors that were increasing the risk of diabetes among the population. 
incarcerate noncompliant patients and enforce the compulsory screening of contacts. Sometimes such discussions cover difficulties associated with health system factors such as remoteness, poor transportation, closed health facilities and poor drug supplies, or factors more closely tied to patients such as the effect(s) of stigma or side effects of medication, these are generally concealed by discourses that position PNG patients as highly problematic and, further, as driving the spread of $\mathrm{TB}$ and drug resistance. Structural factors are submerged beneath discussions of individual (ir) responsibility.

Prioritising individual responsibility over structural social inequalities has several consequences. First, health sector attention is directed towards trying to alter the behaviour of individuals to make them more compliant. It also shifts focus away from the need for structural change: 'victim blaming $\ldots$ is a poor practice that misdirects attention away from assembling more qualified human resources, improving health infrastructure and building stronger health systems that coordinate effectively with the private sector' (Mason et al., 2016, p. 3). This is particularly critical in areas affected by mining, where structural inequities and coordination of services are crucial. Focus on individual behaviour serves as a sleight of hand that obfuscates issues and inequalities. Finally, individualising responsibility deepens the social inequalities between the health care workforce and people infected with $\mathrm{TB}$, leading patients to become less likely to seek diagnosis and to continue treatment.

Health staff also cited cultural beliefs about TB as issues in both diagnosis and treatment adherence. A number of staff stated that symptoms and their cause(s) are frequently the subject of misunderstanding-patients and community members often believe that sorcery is a key issue. Some people believe that treatment with TB medications is pointless or fear that symptoms indicated ensorcellment; consequently, they sought health care too late to be effectively treated. In these discussions, cultural beliefs were posited as a problem and health staff attitudes varied from understanding to frustration and dismissal.

In my experience, it was certainly the case that Lihirians raised concerns about sorcery whenever someone was seriously ill. Some illnesses are perceived as relatively simple and resolvable through biomedical treatment. Yet, other illnesses, including those that do not resolve easily with treatment, are understood to be linked to the untoward actions of another human being. In these cases, it is believed to be important to consider the state of a person's relationship with others and take steps 
to discover the likely culprit and resolve the situation. The state of social relationships is of great importance for Lihirians, as it is for other Papua New Guineans, who understand positive relationships with others, often termed wanbel, to be a source of health (Street, 2014; Troolin, 2018). In the case of $\mathrm{TB}$, Johnson identified a number of cultural models that explained TB spread or symptoms, including that it ran in families and could be inherited, that it was a disease of old people, that it could be passed through food or was caused by sorcery. Most people did not have a contagion model and did not understand germ theory (Johnson, 2004). This differs dramatically to my findings in relation to HIV/AIDS-health education had been readily absorbed and people were actively worried about catching HIV from others via the blood/fluids pathway, particularly from migrants to the islands or if they travelled away from the islands (Hemer, 2015).

In the case of one of the young women discussed above, her mother was unsure about the diagnosis-she was concerned that her daughter's illness was caused by sorcery instead of TB or, alternatively, that sorcery was causing the TB. Despite this, she ensured that her daughter was diagnosed and got treatment. While some literature on Melanesia notes a strict binary between sik bilong marasin (biomedically treatable illness) and sik bilong ples (local illnesses having causes like sorcery; see e.g. Cox \& Phillips, 2015), in Lihir there is no fixed or strict boundary between the two; therefore, a plurality of healthcare approaches is often sought (Macintyre et al., 2005). In this way, suggestions of sorcery do not preclude biomedical treatment. In another reported case, a woman's lymph glands swelled enormously and eventually burst. She was brought into the health centre and diagnosed with extra-pulmonary TB. A nurse commented that people in the village did not believe it was TB, instead deeming it to be sorcery. This is perhaps unsurprising because health education in PNG firmly identifies TB with the principal symptom of coughing, rather than abscesses of the glands that might rupture. Johnson (2004) noted that Lihirians firmly linked TB to weight loss and coughing rather than other symptoms. However, despite these concerns, this woman was diagnosed and successfully completed treatment for TB.

These cases suggest that a belief in sorcery is not necessarily incompatible with biomedical diagnosis and successful treatment of TB. However, narratives at the national level place patient beliefs and compliance at the centre of understanding high rates of TB in PNG. The Chairman of Public Health at the University of Papua New Guinea, Louis Samiak, 
has stated (in relation to TB) that the 'biggest barrier for the moment is cultural beliefs about the causes of diseases ... the first source of help is witchdoctors and local remedies' (cited by Wilson, 2015). This perspective is echoed by Ungugo et al. (2011, p. 423), in a publication that notes the 'clash of culture and science' in TB diagnosis and treatment. The paper lists a range of issues in relation to $\mathrm{TB}$, including inadequate health facilities and drug supply, the lack of diagnostic facilities in the country, a lack of contact screening and physical accessibility of health care, among others. Yet, it lists 'sorcery' and 'witchdoctor' as two of the five article keywords, demonstrating the focus on cultural responsibility and the preclusion of structural inequalities.

Lepani (2012) has critically reviewed the ways in which 'culture' or cultural beliefs are employed in the health field. The key issue that she identified was how cultural attitudes to sexuality were seen as problematic in the Trobriands regarding HIV; however, her points apply equally to the case of TB in PNG. A narrow version of culture, often labelled as 'cultural beliefs', is frequently blamed rather than addressing more complex issues such as social structures and global economic or political forces that shape the spread of infections and methods of diagnosis and treatment. This placement of responsibility on individuals as noncompliant or cultural beliefs as barriers to health care transfers attention from the structural positioning of people who develop $\mathrm{TB}$ and the challenges they face in seeking and continuing treatment.

\section{Conclusions}

The field of global health, for all its rhetoric regarding the socioeconomic and political contexts of diseases such as TB, is the author of policies that pay lip service to the systemic contexts of health, but that are profoundly singular, vertical and removed from context, in practice. Such policies are singularly disease-focused-they pinpoint targets for control and eradication to provide something tangible and achievable on which to focus. These guidelines and targets are then translated to the national level in countries such as PNG, where experts and funding shape health policies and practices with a largely clinical focus.

It requires a concerted effort to trace the impact of the inequalities obfuscated by such policies and, further, to analyse the ways that the policies themselves then compound those inequalities. In the case of 
TB in PNG, some inequalities in infection rates, access to diagnosis and treatment are readily apparent-there exists a clear concern regarding high levels of $\mathrm{TB}$ infection and MDR-TB in particular provinces or locations that are designated as hotspots. These locations attract attention, research and publications, funding, global expertise and new technologies for diagnosis. However, the intensity of this focus has overshadowed TB in the rest of the country.

Analysis of the TB situation in Lihir facilitates a clear illustration of the ways in which, even within relatively wealthy mining enclaves, TB is flourishing and the health system is struggling to maintain the pace. Despite the presence of some of the best health care available in the country, access to health care is not a simple matter for many people on the islands. Moreover, the kind of access required to properly treat TB, which involves inpatient treatment for weeks and then six or more months of daily medications, may be beyond the health system's capabilities. These challenges, rather than being met with understanding about the social inequalities that drive TB and limit access to health care, are often viewed as individual or cultural failures.

In the case of $\mathrm{TB}$, social, political and economic inequalities coalesce in physical form to shape an individual's risk of infection and the development of active TB. Further, they mould that person's access to diagnosis and their course through treatment, in which inequalities may be compounded by the destructive processes of the illness.

\section{References}

Aia, P., Wangchuk, L., Morishita, F., Kisomb, J., Yasi, R., Kal, M. \& Islam, T. (2018). Epidemiology of tuberculosis in Papua New Guinea: Analysis of case notification and treatment outcome data, 2008-2016. Western Pacific Surveillance and Response, 9(2), 1-11.

Bainton, N. (2010). The Lihir destiny: Cultural responses to mining in Melanesia. Canberra, ACT: ANU E Press. doi.org/10.22459/LD.10.2010

Banks, G. (2005). Globalisation, poverty, and hyperdevelopment in Papua New Guinea's mining sector. Focaal - Journal of Global and Historical Anthropology, 46, 128-146. doi.org/10.3167/092012906780786799

Banks, G. (2008). Understanding 'resource' conflicts in Papua New Guinea. Asia Pacific Viewpoint, 49(1), 23-34. doi.org/10.1111/j.1467-8373.2008.00358.x 
Beer, B. (2018). Gender and inequality in a postcolonial context of large-scale capitalist projects in the Markham Valley, Papua New Guinea. The Australian Journal of Anthropology, 29, 348-364. doi.org/10.1111/taja.12298

Bentley, K. (2010). Lihir social demographic health survey. Canberra, ACT: Centre for Environmental Health Pty Ltd for Newcrest Mining Ltd.

Cox, J. \& Phillips, G. (2015). Sorcery, Christianity and the decline of medical services. In M. Forsyth \& R. Eves (Eds), Talking it through: Reponses to sorcery and witchcraft beliefs and practices in Melanesia (pp. 37-54). Canberra, ACT: ANU Press. doi.org/10.22459/TIT.05.2015.02

Cross, G. B., Coles, K., Nikpour, M., Moore, O. A., Denholm, J., McBride, E. S., ... Pellegrini, M. (2014). TB incidence and characteristics in the remote gulf province of Papua New Guinea: A prospective study. BMC Infectious Diseases, 14(93), 1-10. doi.org/10.1186/1471-2334-14-93

Department of Health, Government of Papua New Guinea. (2011). PNG National Tuberculosis Management Protocol. Waigani, Port Moresby. Retrieved from www. adi.org.au/wp-content/uploads/2016/11/National-Tuberculosis-ManagementProtocol-PNG-2011.pdf

Department of Health, Government of Papua New Guinea. (2012). Health Service Delivery Profile, Papua New Guinea. Retrieved from pdf4pro.com/cdn/healthservice-delivery-profile-papua-new-guinea-254938.pdf

Dixon, J. \& Macdonald, H. (2018). Globalised tuberculosis control in local worlds. Anthropology Southern Africa, 41(4), 247-256. doi.org/10.1080/23323256. 2018.1547116

Elbeck, O. (2015). Ethical issues in tuberculosis control. Turkish Thoracic Journal, 16, 73-85. doi.org/10.5152/ttd.2014.4134

Farmer, P. E. (2000). The consumption of the poor: Tuberculosis in the 21 st century. Ethnography, 1(2), 183-216. doi.org/10.1177/14661380022230732

Farmer, P. E. (2001). Infections and inequalities: The modern plagues. Berkeley, CA: University of California Press.

Farmer, P. E., Nizeye, B., Stulac, S. \& Keshavjee, S. (2006). Structural violence and clinical medicine. PLOS Medicine, 3(10), 1686-1691. doi.org/10.1371/ journal.pmed.0030449

Feng, J. Y., Huang, S. F., Ting, W. Y., Chen, Y. C., Lin, Y. Y., Huang, R. M., ... $\mathrm{Su}$, W. J. (2012). Gender difference in treatment outcomes of tuberculosis patients in Taiwan: A prospective observational study. Clinical Microbiology and Infection, 18, E331-E337. doi.org/10.1111/j.1469-0691.2012.03931.x 
Gilpin, C. M., Simpson, G., Vincent, S., O’Brien, T. P., Knight, T. A., Globan, M., ... Konstantinos, A. (2008). Evidence of primary transmission of multidrug resistant tuberculosis in the Western Province of Papua New Guinea. Medical Journal of Australia, 188(3), 148-152.

Hargreaves, J. R., Boccia, D., Evans, C. A., Adato, M., Petticrew, M. \& Porter, J. D. H. (2011). The social determinants of tuberculosis: From evidence to action. American Journal of Public Health, 101(4), 654-662. doi.org/10.2105/ AJPH.2010.199505

Harper, I. (2010). Extreme condition, extreme measures? Compliance, drug resistance and the control of tuberculosis. Anthropology \& Medicine, 17(2), 201-214. doi.org/10.1080/13648470.2010.493606

Harper, I. \& Parker, M. (2014). The politics and anti-politics of infectious disease control. Medical Anthropology, 33(3), 198-205. doi.org/10.1080/01459740 .2014 .892484

Hemer, S. R. (2001). Illness and health care in the Lihir islands [Unpublished report]. LGL.

Hemer, S. R. (2015). Breaking silences and upholding confidences: Responding to HIV in the Lihir Islands, Papua New Guinea. Medical Anthropology, 34(2), 124-138. doi.org/10.1080/01459740.2014.944263

Horner, J., Wood, J. G. \& Kelly, A. (2013). Public health in/as 'national security': Tuberculosis and the contemporary regime of border control in Australia. Critical Public Health, 23(4), 418-431. doi.org/10.1080/09581596.2013.8 24068

Howes, S., Mako, A. A., Swan, A., Walton, G., Webster, T. \& Wiltshire, C. (2014). A lost decade? Service delivery and reforms in Papua New Guinea 20022012. Canberra, ACT: The National Research Institute and Development Policy Centre.

Janes, C. R. \& Corbett, K. K. (2009). Anthropology and global health. Annual Review of Anthropology, 38, 167-183. doi.org/10.1146/annurevanthro-091908-164314

Johnson, P. (2004). 'TB, well that is a long-term punishment. Some people give their life to the medicine to make themselves better': A short ethnographic perspective on tuberculosis and TB treatment from Lihir Island [Unpublished report].

Lepani, K. (2012). Islands of love, islands of risk: Culture and HIV in the Trobriands. Nashville, TN: Vanderbilt University Press. 
Ley, S. D. (2014). Molecular epidemiology of tuberculosis in selected sites across Papua New Guinea (Unpublished doctoral thesis). University of Basel, Switzerland.

Ley, S. D., Riley, I. \& Beck, H. (2014). Tuberculosis in Papua New Guinea: From yesterday until today. Microbes and Infection, 16(8), 607-614. doi.org/10.1016/ j.micinf.2014.06.012

Ley, S. D., Harino, P., Vanuga, K., Kamus, R., Carter, R., Coulter, C., ... Beck, H. (2014). Diversity of mycobacterium tuberculosis and drug resistance in different provinces of Papua New Guinea. BMC Microbiology, 14, 307. doi.org/10.1186/s12866-014-0307-2

Macintyre, M. (2010). Foreword. In N. Bainton (Ed.), The Libir destiny: Cultural responses to mining in Melanesia. Canberra, ACT: ANU E Press. doi.org/ 10.22459/LD.10.2010

Macintyre, M., Foale, S., Bainton, N. \& Moktel, B. (2005). Medical pluralism and the maintenance of a traditional healing technique on Lihir, Papua New Guinea. Pimatisiwin: A Journal of Aboriginal and Indigenous Community Health, 3(1), 87-99.

Magnussen, L., Ehiri, J. \& Jolly, P. (2004). Comprehensive versus selective primary health care: Lessons for global health policy. Health Affairs, 23(3), 167-176. doi.org/10.1377/hlthaff.23.3.167

Mason, P. \& Degeling, C. (2016). Beyond biomedicine: Relationships and care in tuberculosis prevention. Bioethical Inquiry, 13(1), 31-34. doi.org/10.1007/ s11673-015-9697-6

Mason, P. H., Snow, K., Asugeni, R., Massey, P. D. \& Viney, K. (2016). Tuberculosis and gender in the Asia-Pacific Region. Australia and New Zealand Journal of Public Health, 41(3), 227-229. doi.org/10.1111/1753-6405.12619

Norbis, L., Alagna, R., Tortoli, E., Codecasa, L. R., Migliori, G. B. \& Cirillo, D. M. (2014). Challenges and perspectives in the diagnosis of extrapulmonary tuberculosis. Expert Review of Anti-infective Therapy, 12(5), 633-647. doi.org/ $10.1586 / 14787210.2014 .899900$

Ortblad, K. F., Salomon, J. A., Barnighausen, T. \& Atun, R. (2015). Stopping tuberculosis: A biosocial model for sustainable development. The Lancet, 386(10010), 2354-2362. doi.org/10.1016/S0140-6736(15)00324-4

Parker, M. \& Allen, T. (2014). De-politicising parasites: Reflections on attempts to control the control of neglected tropical diseases. Medical Anthropology, 33(3), 223-239. doi.org/10.1080/01459740.2013.831414 
Silva, D. S., Dawson, A. \& Upshur, R. E. G. (2016). Reciprocity and ethical tuberculosis treatment and control. Bioethical Inquiry, 13(1), 75-86.

Simpson, G. (2011). Multidrug-resistant tuberculosis on Australia's northern border. Internal Medicine Journal, 41(11), 759-761. doi.org/10.1111/j.14455994.2011.02588.x

Street, A. (2014). Biomedicine in an unstable place: Infrastructure and personhood in a Papua New Guinean hospital. Durham, NC: Duke University Press. doi. org/10.1215/9780822376668

Taufa, T., Jones, M., Day, G. \& Mea, V. (1992). Baseline health survey of Lihir Islanders, April 1991 [Report]. Hawthorn, Vic.: NSR Environmental Consultants Pty Ltd.

Thomas, E. G., Barrington, H. E., Lokuge, K. M. \& Mercer, G. N. (2010). Modelling the spread of tuberculosis including drug resistance and HIV: A case study in Papua New Guinea's Western Province. Australia and New Zealand Applied and Industrial Mathematics Journal, 52, 26-45.

Ting, W. Y., Huang, S. F., Lee, M. C., Lin, Y. Y., Lee, Y. C., Feng, J. Y. \& Su, W. J. (2014). Gender disparities in latent tuberculosis infection in high-risk individuals: A cross-sectional study. PLoS ONE, 9(11), e110104.

Troolin, D. (2018). Wanbel: Conflict, reconciliation and personhood among the Sam people, Madang Province (Unpublished doctoral thesis). University of Adelaide, Australia.

Ungugo, K., Hall, J. \& Attia, J. (2011). Implementing tuberculosis control in Papua New Guinea: A clash of culture and science? Journal of Community Health, 36, 423-430. doi.org/10.1007/s10900-010-9324-8

United Nations. (2018). United to end tuberculosis: An urgent global response to a global epidemic (Opening statement and Plenary 1). Retrieved from www. unmultimedia.org/avlibrary/asset/2245/2245992/

Wilson, C. (2015, 25 March). Multi-drug resistance adds to tuberculosis epidemic in Papua New Guinea. Inter Press Service News Agency. Retrieved from www. ipsnews.net/2015/03/multi-drug-resistance-adds-to-tuberculosis-epidemic-inpapua-new-guinea/

Wiltshire, C. \& Mako, A. (2014). Financing PNG's free primary health care policy: User fees, funding and performance. Development Policy Centre Australian National University \& National Research Institute, PNG. Retrieved from devpolicy.org/publications/reports/PEPE/Financing-PNGs-free-primaryhealth-care-policy-user-fees-funding-and-performance.pdf 
Wingfield, T., Tovar, M. A., Huff, D., Boccia, D., Saunders, M. J., Datta, S., ... Evans, C. (2016). Beyond pills and tests: Addressing the social determinants of tuberculosis. Clinical Medicine, 16(6), s79-s91. doi.org/10.7861/clinmedicine. 16-6-s79

World Health Organization. (2006). The Stop TB Strategy: Building on and enhancing DOTS to meet the TB-related Millennium Development Goals. Geneva, Switzerland: World Health Organization.

World Health Organization. (2012). Accelerating work to overcome the global impact of neglected tropical diseases: A roadmap for implementation. Retrieved from www. who.int/neglected_diseases/NTD_RoadMap_2012_Fullversion.pdf

World Health Organization. (2015). Global tuberculosis report 2015. Retrieved from apps.who.int/iris/handle/10665/191102

World Health Organization. (2018). Global tuberculosis report 2018. Retrieved from reliefweb.int/report/world/global-tuberculosis-report-2018

World Health Organization. (2019). Global tuberculosis report 2019. Retrieved from www.who.int/tb/publications/global_report/en/

Zimmer-Tamakoshi, L. (2016). Inequality and changing masculinities among the Gende in Papua New Guinea: The 'good,' the 'bad' and the 'very bad'. The Asia Pacific Journal of Anthropology, 17(3-4), 250-267. doi.org/10.1080/14442213. 2016.1186216 
This text is taken from Unequal Lives: Gender, Race and Class in the Western Pacific, edited by Nicholas A. Bainton, Debra McDougall, Kalissa Alexeyeff and John Cox, published 2021 by ANU Press, The Australian National University, Canberra, Australia.

doi.org/10.22459/UE.2020.05 